
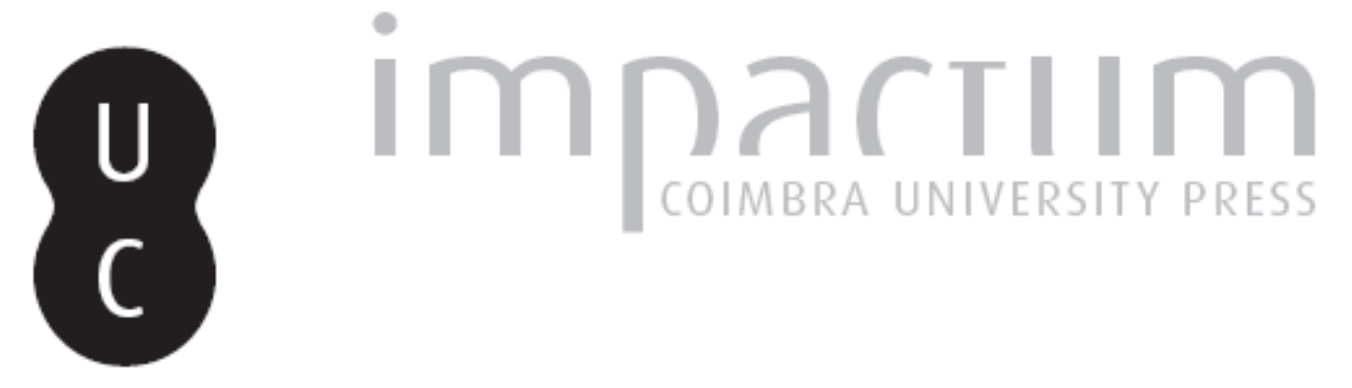

\title{
Estação romana do Cerrado do Castelo
}

Autor(es): $\quad$ Ferreira, Marisol Aires; Faria, João Carlos Lázaro

Publicado por: Imprensa da Universidade de Coimbra

URL persistente:

URl:http://hdl.handle.net/10316.2/45528

DOI:

DOI:https://dx.doi.org/10.14195/1647-8657_30_6

Accessed : $\quad$ 26-Apr-2023 14:14:58

A navegação consulta e descarregamento dos títulos inseridos nas Bibliotecas Digitais UC Digitalis, UC Pombalina e UC Impactum, pressupõem a aceitação plena e sem reservas dos Termos e Condições de Uso destas Bibliotecas Digitais, disponíveis em https://digitalis.uc.pt/pt-pt/termos.

Conforme exposto nos referidos Termos e Condições de Uso, o descarregamento de títulos de acesso restrito requer uma licença válida de autorização devendo o utilizador aceder ao(s) documento(s) a partir de um endereço de IP da instituição detentora da supramencionada licença.

Ao utilizador é apenas permitido o descarregamento para uso pessoal, pelo que o emprego do(s) título(s) descarregado(s) para outro fim, designadamente comercial, carece de autorização do respetivo autor ou editor da obra.

Na medida em que todas as obras da UC Digitalis se encontram protegidas pelo Código do Direito de Autor e Direitos Conexos e demais legislação aplicável, toda a cópia, parcial ou total, deste documento, nos casos em que é legalmente admitida, deverá conter ou fazer-se acompanhar por este aviso.

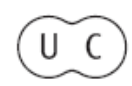


FACULDADE DE LETRAS

INSTITUTO DE ARQUEOLOGIA

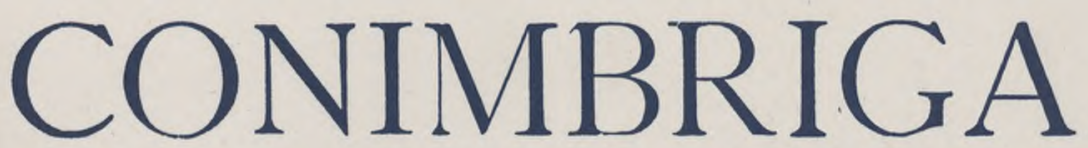

VOLUME XXX

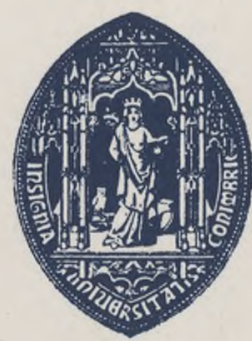

UNIVERSIDADE DE COIMBRA 
MARISOL AIRES FERREIRA

Técnica responsável pelo sector do Património Cultural da Câmara Municipal de Grândola

Jõ̃o CARLOS LÁZARO FARIA

Técnico responsável pelo sector do Património Cultural da Câmara Municipal de Alcácer do Sal

\section{ESTAÇÃO ROMANA DO CERRADO DO CASTELO \\ (ESCOLAPRIMÁRIA-GRÂNDOLA)}

«Conimbriga» XXX (1991), p. 95-104

Resumo: No Cerrado do Castelo (Grândola), em terrenos de uma escola primária, os autores descobriram vestígios romanos: umas termas e dois fornos para fabrico de imbrices. A reduzida área descoberta não permite a identificação da estação: tratar-se-á de uma villa, mansio ou mutatiol Os escassos materiais recolhidos oscilam entre os séculos I e III/IV d. C.

RÉSUMÉ: Dans la cour de l'école primaire à Cerrado do Castelo (Grândola), les auteurs ont fouillé des vestiges romains: des thermes et deux fours pour la cuisson d'imbrices. L'aire réduite qui a été fouillée ne permet pas l'identification de la nature du site. Il peut s'agir d'une villa, mansio ou mutatio. Les céramiques ramassées datent du Ier jusqu'au III -IVe siècles. 
(Página deixada propositadamente em branco) 


\section{ESTAÇÃO ROMANA DO CERRADO DO CASTELO (ESCOLA PRIMÁRIA — GRÂNDOLA)}

A referência mais antiga que possuímos do Cerrado do Castelo remonta aos inícios do nosso século quando Leite de Vasconcelos, ao visitar o concelho de Grândola, constatou o seguinte:

"Contíguo à Vila de Grândola há dois campos largos e planos cortados por uma estrada que fica sobranceira à várzea do rio Davino, chamados, o da esquerda, para quem sai da vila, Castelo, e o da direita, Castelinho. O primeiro é, além disso, cortado por outra estrada.

Nestes dois campos, que ocupam grande extensão, aparece numeroso entulho, constituido por cacos, e também alguns restos de paredes e lanços de formigão (opus signinum). Entre os cacos reconheci restos de vasilhas finas e telhões (...). Nos mesmos campos apareceram várias moedas de bronze, algumas das quais vieram para o Museu: de Augusto, de Alexandre Severo (séc. III), de Constantino (séc. IV) e uma de Emérita (...). Estes campos, apesar do nome que o povo lhes deu, não podem considerar-se castros, são, porém, assento de uma antiga Grândola"^).

Nos anos quarenta, com a construção neste local das instalações da escola primária, muitos dos vestígios então referidos foram destruídos ou bastante danificados.

Após uma visita dos signatários ao local, foi, porém, possível ainda identificar alguns restos arqueológicos no recinto da escola e terrenos adj acentes, tendo sido levada a efeito uma ampla intervenção, superiormente autorizada, faseada em duas campanhas, uma em 1989 e outra em 1990.

Os objectivos fundamentais destas campanhas prendiam-se com a realização de sondagens no terreno contíguo à escola—local onde estava

(9 José Leite de Vasconcelos, Excursão Archeologica à Extremadura Transtagana, in "O Archeologo Português", vol. XIX, Lisboa, 1914, pág. 310. 
prevista a construção de novas instalações - e também a tentativa de delimitar com maior exactidão a real extensão da estação arqueológica.

Foi possível, assim, individualizar dois núcleos a escavar: um primeiro núcleo contíguo à cantina da escola e um segundo núcleo situado imediatamente junto à entrada da escola.

No primeiro núcleo, foram descobertas uma série de estruturas do período romano, formando compartimentos entre si, cujos pavimentos são de opus signinum. Não foi encontrado qualquer nível arqueológico, pois toda esta zona estava, antes desta intervenção, perfeitamente visível, tendo-se procedido unicamente a um mero trabalho de limpeza para colocar estruturas à vista.

No segundo caso, foram detectados um conjunto de estruturas com muros de xisto, ligados por argamassa, tecnicamente semelhantes aos já referidos, e que corresponderiam a umas termas ou balneário da época romana.

As construções ora descobertas são constituídas por quatro pequenos tanques, uma piscina e duas salas.

Todo o conjunto foi bastante afectado aquando da construção da escola primária, não se detectando qualquer nível arqueológico bem definido, mas apenas camadas sucessivas de revolvimento e entulho com cerâmica vidrada e outros objectos dos anos 50 deste século, tendo sido apenas recolhida uma pouco representativa colecção de materiais romanos.

A um nível inferior ao pavimento da piscina, foram descobertos dois fornos para o fabrico de imbrices, cuja construção deverá ter-se verificado numa época de abandono deste local.

Os fornos são circulares, tendo sido utilizados na sua construção lateres tubulares, pertença certamente de um hypocaustum, posteriormente reaproveitados e ligados por argamassa.

A cobertura destes fornos era abobadada, formada por uma fina camada de argamassa a qual assentava igualmente numa pouca espessa camada de argila.

Formados apenas por uma câmara circular, neles se encontraram abundantes imbrices, alguns dos quais marcados com dedadas feitas quando a pasta ainda estava fresca. Abase era constituída unicamente por terra argilosa e fragmentos de lateres e pedra. Restos de carvão foram encontrados também no forno. 


\section{CATÁLOGO}

1. PRATO COVO. Bordo revirado para dentro, paredes arqueadas.

Pasta alaranjada, dura, micácea, textura folheada, de pequeno grão, atingindo os $2 \mathrm{~mm}$. Superfícies beges com manchas acinzentadas do contacto com o fogo. Diâm. $-20 \mathrm{~cm}$.

2. POTE. Bordo amendoado com ombros quase arredondados.

Pasta alaranjada de textura folheada, com pequenas areias e minúsculas micas, com pequenas fendas. Superfícies rosadas alisadas com engobe ocre-alaranjado com bandas estreitas.

Diâm. $-18 \mathrm{~cm}$.

3. PRATO COVO. Bordo amendoado, com cotovelo bem marcado.

Pasta bege, de textura folheada, com pequenas fendas e areias, sem micas visíveis. Superfície bege, alisada.

Diâm.- $22 \mathrm{~cm}$.

4. POTE. Bordo oblíquo, ligeiramente côncavo no dorso e ombros arredondados, com vestígios de asa de fita a nascer na sobeira do bordo.

Pasta acinzentada, micácea e arenosa. Superfície externa com engobe cinzento claro e bandas estreitas de alisamento.

Diâm.-12 cm.

5. ALGUIDAR. Bordo em pingo, paredes arqueadas.

Pasta alaranjada, dura, ligeiramente micácea, de textura folheada, com pequenas fendas e alvéolos. Superfície bege-rosada.

Diâm .- $42 \mathrm{~cm}$.

6. POTE. Bordo ligeiramente revirado para fora, ombros quase rectos.

Pasta alaranjada, branda, muito micácea, relativamente depurada, com pequenas areias e fendas.

Diâm. $-16 \mathrm{~cm}$.

7. POTE. Bordo revirado para fora e arqueado, ombros convergentes e quase rectos. Pasta arenosa, queimada pela cozedura.

Diâm. -14 cm. ${ }^{8}$

8. POTE. Bordo ligeiramente revirado para fora, com arranque de asa a nascer do bordo.

Pasta alaranjada, com textura folheada, com pequenas fendas e alvéolos, minúsculas micas e pequenas areias, com nódulos ferruginosos. Superfície bege com bandas de engobe alaranjado.

Diâm.- 14 cm. 
9. ALGUIDAR. Bordo em pingo, paredes muito divergentes.

Pasta alaranjada, de textura folheada, com pequenos grãos, micas e alvéolos. Superfície bege alaranjada. Orifício de um centímetro de diâmetro junto ao bordo. Diâm.- 37 cm.

10. PRATO COVO. Bordo de forma triangular.

Pasta alaranjada, de textura arenosa, com pequenos alvéolos e micas. Superfície bege alaranjada, com engobe ocre vermelho no bordo e bandas horizontais no seu interior.

Diâm.- Impossível de determinar.

\section{IMBREX.}

Pasta porosa, com fendas, alvéolos e nódulos atingindo os $2 \mathrm{~cm}$. Tonalidade amarelada. Superfície externa com marcas bem profundas de alisamento, feito com os dedos. Não ilustrado.

12. TALHA. Bordo em forma de rim, dobrado sobre os ombros.

Pasta ocre-alaranjada, cinzenta esverdeada para o seu interior, com pequenas areias e minúsculas micas. Superfície rosada com manchas negras do contacto com o fogo.

Diâm.- $39 \mathrm{~cm}$.

13. TALHA. Bordo em forma de rim, dobrado sobre os ombros.

Pasta de tonalidade bege alaranjada de aspecto arenoso, com pequenos alvéolos. Superfície bege.

Diâm.- 36 cm.

14. TALHA. Bordo ligeiramente engrossado.

Pasta castanha, dura, de aspecto arenoso, muito micácea, com pequenos grãos e alvéolos. Superfície muito micácea.

Diâm.- 34 cm.

15. TALHA. Bordo em forma de rim, achatado.

Pasta acastanhada, com pequenas areias, de textura folheada, ligeiramente micácea. Superfície bege alisada.

Diâm.- $30 \mathrm{~cm}$.

16. TALHA. Bordo engrossado, corpo possivelmente ovoide.

Pasta queimada da cozedura, micácea. Superfície cinzenta escura.

Diâm.- $36 \mathrm{~cm}$.

17. TALHA. Bordo ligeiramente engrossado.

Pasta castanha escura, dura, de aspecto folheado, de grãos pequenos, micácea, com pequenas fendas e alvéolos, superfície acastanhada.

Diâm.- $30 \mathrm{~cm}$.

Conimbriga, 30 (1991), 95-104 
18. TALHA. Bordo engrossado, corpo possivelmente ovoide.

Pasta queimada da cozedura, micácea. Conserva vestígios de um grafito junto ao bordo.

Diâm.- $36 \mathrm{~cm}$.

19. TALHA. Bordo ligeiramente engrossado e canelado.

Pasta de tonalidade castanha escura, com textura folheada, de pequeno grão, atingindo os $2 \mathrm{~mm}$, minúsculas micas e pequenos alvéolos e fendas. Superfície acastanhada.

Diâm.- $30 \mathrm{~cm}$.

20. TALHA. Bordo engrossado e possivelmente ovoide.

Pasta de tonalidade castanha alaranjada e castanha escura para o interior. Textura arenosa, com pequenas areias e minúsculas micas. Superfície alisada de tom alaranjado.

Diâm.- 44 cm.

21. TALHA. Bordo ligeiramente engrossado e canelado.

Pasta de tonalidade alaranjada, branda, com pequenas micas, de textura folheada, com pequeno grão e fendas. Superfície alaranjada, mais clara que a pasta.

Diâm.- 24 cm.

22. TALHA. Bordo engrossado.

Pasta alaranjada, dura, ligeiramente micácea, de textura folheada, com pequenas fendas e alvéolos, com areias atingindo $1 \mathrm{~cm}$. Superfície bege alaranjada.

Diâm. - 26 cm.

23. TALHA. Bordo arqueado para fora.

Pasta de tonalidade alaranjada e acastanhada para o interior devido à cozedura. Micácea, com pequenas fendas e alvéolos.

Diâm.- Impossível de determinar.

24. TALHA. Bordo engrossado, corpo possivelmente ovoide.

Pasta acastanhada, de aspecto arenoso, com pequenas fendas, alvéolos e minúsculas micas. Superfície bege rosada.

Diâm.- 36 cm.

\section{FRAGMENTO DE TAÇA DE TERRA SIGILLATA ITÁLICA DA FORMA} RETTERLING 5

Pasta rosada, branda, micro-granulosa, com pequenas calcites. Verniz castanho-alaranjado, de brilho acetinado.

Bordo reentrante, com o interior convexo. Parede rectilínea e oblíqua. Relevo aplicado em espiral.

Diâm.-12 cm. 


\section{CONCLUSÕES}

Numa pequena elevação, os vestígios arqueológicos distribuem-se por uma área ainda considerável. Os terrenos que circundam este local são bastante férteis, propícios para a agricultura e criação de gado. A proximidade de uma linha de água, a ribeira de Grândola, assim como a existência de uma barragem romana $\left(^{2}\right)$ situada sensivelmente a $2 \mathrm{~km}$ a

$\left.{ }^{2}\right)$ A primeira referência sobre a barragem romana do Pego da Moura é-nos dada por M. Mateus que nos faz a seguinte descrição:

“(•••) no extremo sul da vila de Grândola houve uma povoação romana no sítio do Castelo e Castelinho (e talvez Cerrado do Arraial) como se vê nas trincheiras das estradas que partem naquela direcção.

Foi o centro de exploração rural da actual várzea de Grândola, que deve ter atingido um alto grau de perfeição, pois me consta terem nela sido encontrados canos, o que denota a existência de culturas irrigadas, bem como a albufeira ou represa no sítio deste nome, onde ainda existe grande parte do muro primitivo, que me parece de construção romana pela alvenaria.

Posteriormente foi o muro reforçado por outra construção muito diferente e entre cujos contrafortes há restos de uma abóbada duma azenha que utilizaria a energia da queda de água produzida pela represa primitiva já assoreada pelos materiais transportados pelas águas nelas retidas.

Carvalho da Costa, autor da Corografia Portuguesa, dá-nos notícia que no sítio de Corte Galego se encontram muitos canos de água que, ainda hoje, lavrando-se as terras, se descobrem encaminhados para um sítio a que chamam represas ou antes a Horta pois supomos que a água das nascentes, que surgiram entre Corte Galego e a Horta, fosse utilizada nesta, como o nome indica, e que a água do barranco que vem do sul e nascente, retida na albufeira da Represa, fosse aproveitada na rega do vale a jusante (...) (Manuel Mateus, Grândola Antiga, "Album Alentejano" p. 1052-1053).

A barragem do Pego da Moura situa-se na Fonte dos Narizes, junto do lugar das Represas. Aqui apresentamos uma breve descrição dela.

A barragem consiste num muro de planta rectilínea, com um comprimento incial de cerca de $40 \mathrm{~m}$, possuindo actualmente a altura máxima de $3 \mathrm{~m}$ e a espessura de 2,90 m, com 6 contrafortes. Possui uma dupla parede, cujo troço inicial se separou e basculou. Os contrafortes têm a espessura de $2,70 \mathrm{~m}$, o comprimento de $2,90 \mathrm{~m}$ e o afastamento de $2,50 \mathrm{~m}$.

No que diz respeito à estrutura do muro, trata-se de uma construção em opus incertum, constituindo o núcleo, revestido de ambos os lados por dois paramentos de blocos arrumados, dispostos em fiadas aproximadamente paralelas, que se prolongam em continuidade, pelos contrafortes. Foram também utilizados lateres e opus signinum na sua construção.

Um estudo detalhado deste monumento está em preparação pelos autores deste artigo e outros investigadores, o qual deverá ser conhecido oportunamente. 
sul desta estação, a uma cota mais elevada, iria proporcionar uma fácil irrigação dos terrenos de cultivo, bem como facilitar o abastecimento de água às termas romanas.

A identificação de umas termas neste sítio pode indicar a existência de uma villa romana, bem como a de uma mutatio ou mansio.

Esta última hipótese poderá sair fortalecida se tivermos em consideração a situação geográfica destas ruínas, ou seja, entre duas cidades romanas, Salada (Alcácer do Sal) e Mirobriga (Santiago do Cacém).

Teríamos assim um edifício à beira da estrada, onde os viajantes podiam encontrar alojamento, tomar alimento, mudar os animais $\left(^{3}\right)$.

De qualquer modo não devemos menosprezar o facto de estarmos em presença de uma villa $\left({ }^{4}\right)$, cujas termas ou balneários poderão ter sido abandonadas antes da exploração agrícola e, por isso, embora a residência tenha sido abandonada pelo proprietário, continuou a ser agricultada pelos criados $\left({ }^{5}\right)$.

No presente caso, uma situação deste tipo explicaria a construção em plena época romana dos fornos de imbrices na zona da piscina e aproveitando, como referimos, alguns materiais de construção do hypocaustum.

Infelizmente, a falta de níveis arqueológicos bem conservados, a quase inexistência de espólio datável, a situação insólita desta estação no recinto de uma escola - que levanta problemas acerca da continuidades ou não dos trabalhos, constituem factores que explicam de momento todas as dúvidas levantadas.

Por último, refira-se que, ainda assim, o estudo do material arqueológico exumado permite situar cronologicamente esta estação entre os sécs. I e III/IV d. C.

(3) Cfr. Jorge de Alarcáo, 1990, p. 422.

$\left.{ }^{4}\right)$ Num terreno contíguo à estação romana do Cerrado do Castelo, apareceu uma sepultura de inumação do período romano, em data que se ignora, formada por lateres, os quais ainda se encontram na posse do proprietário, donde foi exumado um colar de ouro e berilos verdes, um anel de sinete do mesmo material, primitivamente com gema engastada, que faz parte das colecções do Museu Nacional de Arqueologia de Lisboa. Cfr. catálogo Tesouros da Arqueologia Portuguesa, Lisboa, p. 10 e 17, n. ${ }^{\text {s }}$ 142 e 143. Ora, é do conhecimento geral que muitas destas necrópoles aparecem frequentemente associadas a villae.

$\left(^{5}\right)$ J. Alarcáo, O. cit., 1983, p. 116. 


\section{BIBLIOGRAFIA}

Alarcão, Jorge de, Portugal Romano, 1973.

AlarCão, Jorge de, O Domínio Romano, in Nova História de Portugal., dir. Joel Serrão e A. H. de Oliveira Marques, vol. I, Lisboa 1990, p. 343-489.

Catálogo Tesouros da Arqueologia Portuguesa, Lisboa.

AlarCão, Jorge de, Cerâmica comum Local e Regional de Conimbriga, Coimbra 1974.

Delgado, Manuela, Mayet, Francoa, Alarcão, Adilia, Les sigillées «Fouilles de Conimbriga», vol. IV, Paris.

Mateus, Manuel, Grândola Antiga, in “Album Alentejano”, s. d., p. 1052-1053.

Nolen, Jeannette U. Smit., Cerâmica comum de Necrópoles do Alto Alentejo, 197J.

Quíntela, Antonio de Carvalho, et alii, Aproveitamentos Hidráulicos Romanos a Sul daTejo, Lisboa 1986.

Vasconcelos, José Leite de, Excursão Archeològica à Extremadura Transtagana, in "O Archeologo Português", vol. XIX Lisboa, 1914. 


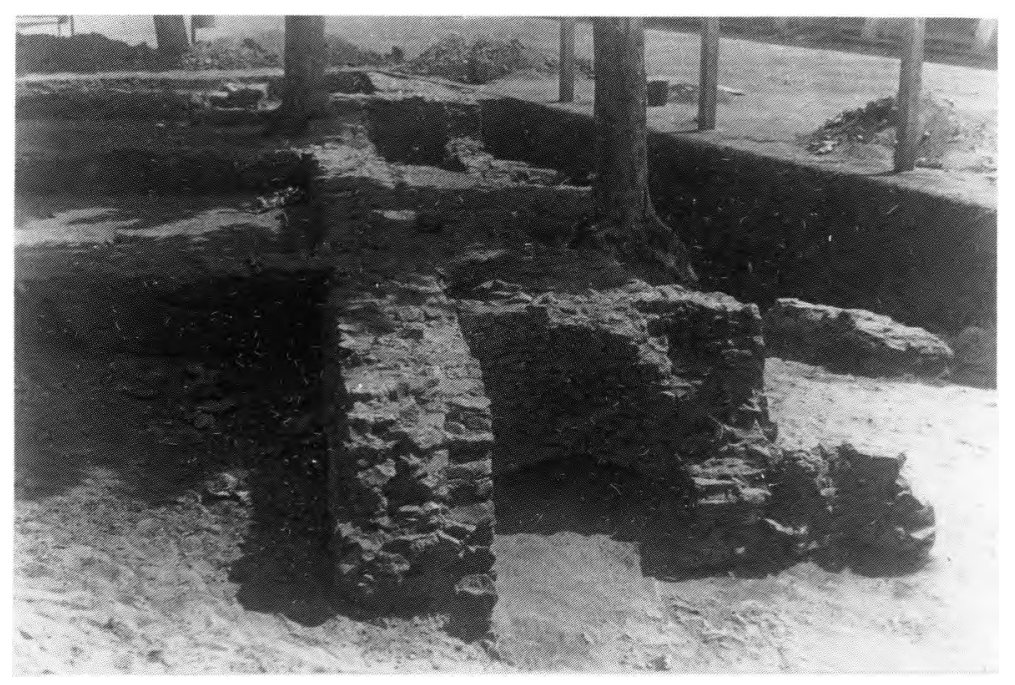

FIG. 1

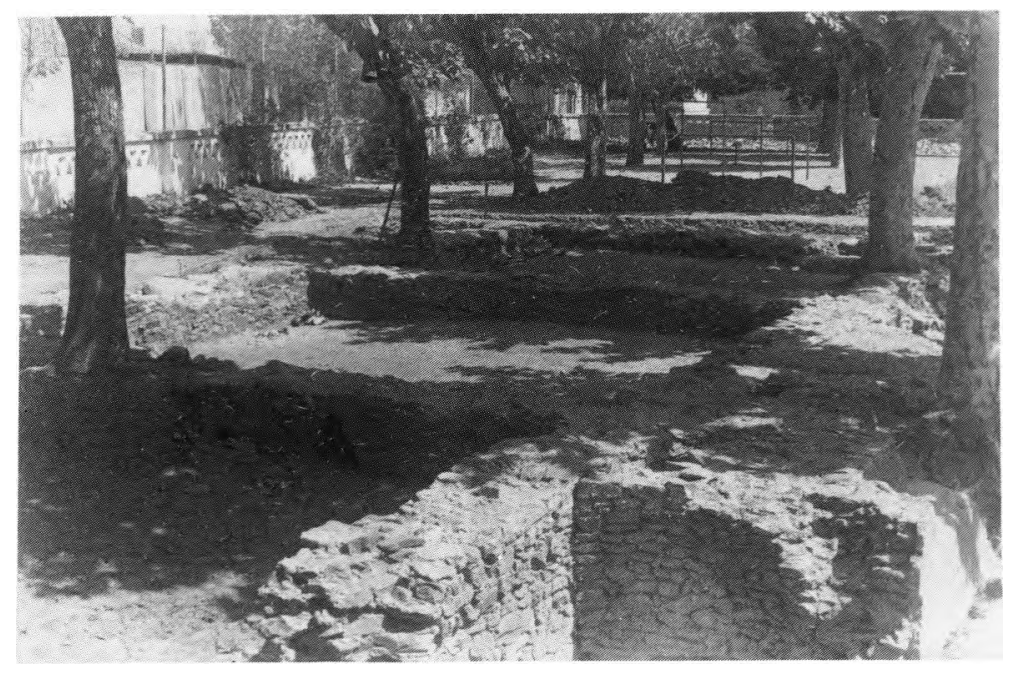

FIG. 2 


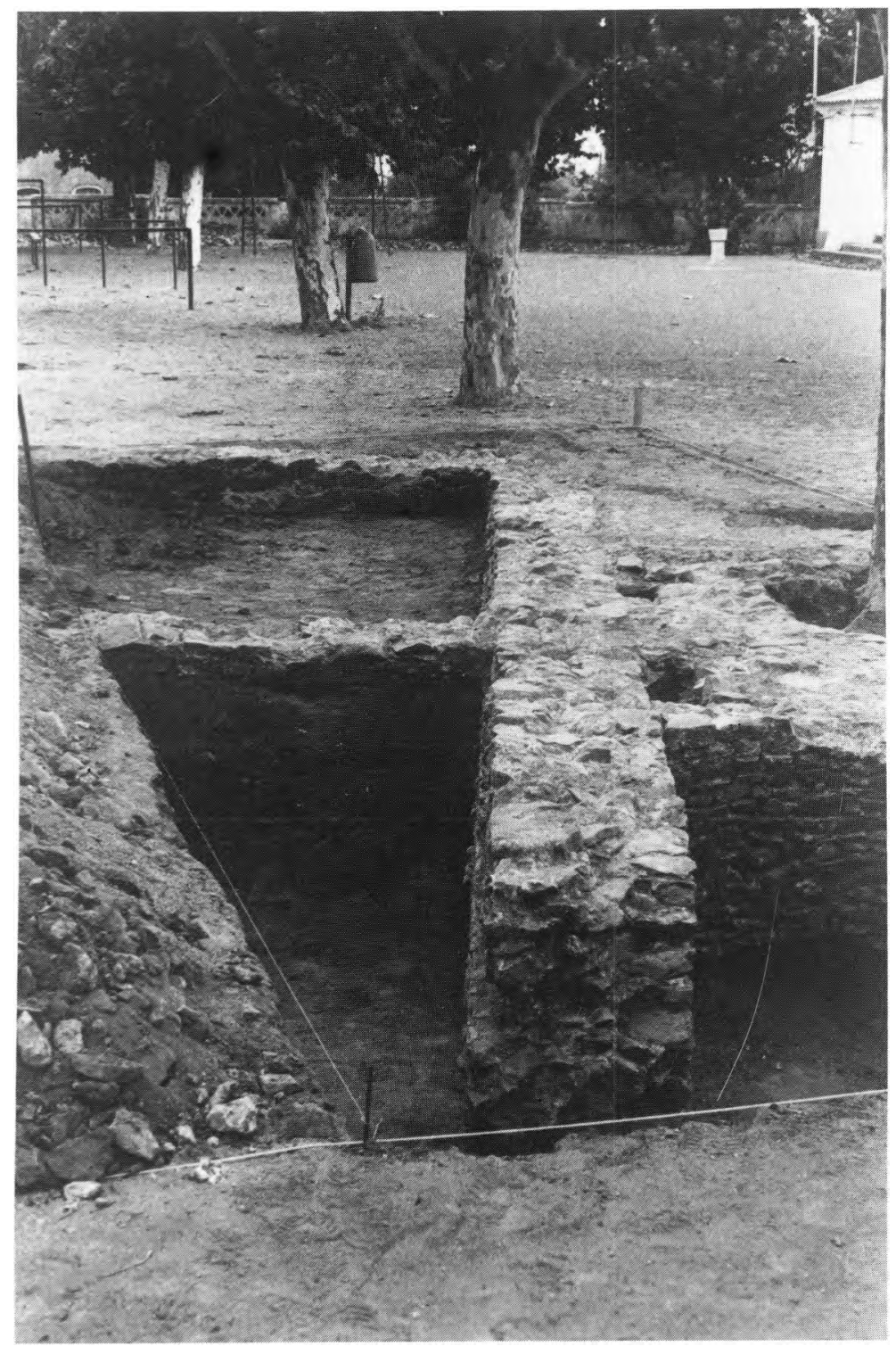

FIG. 3 


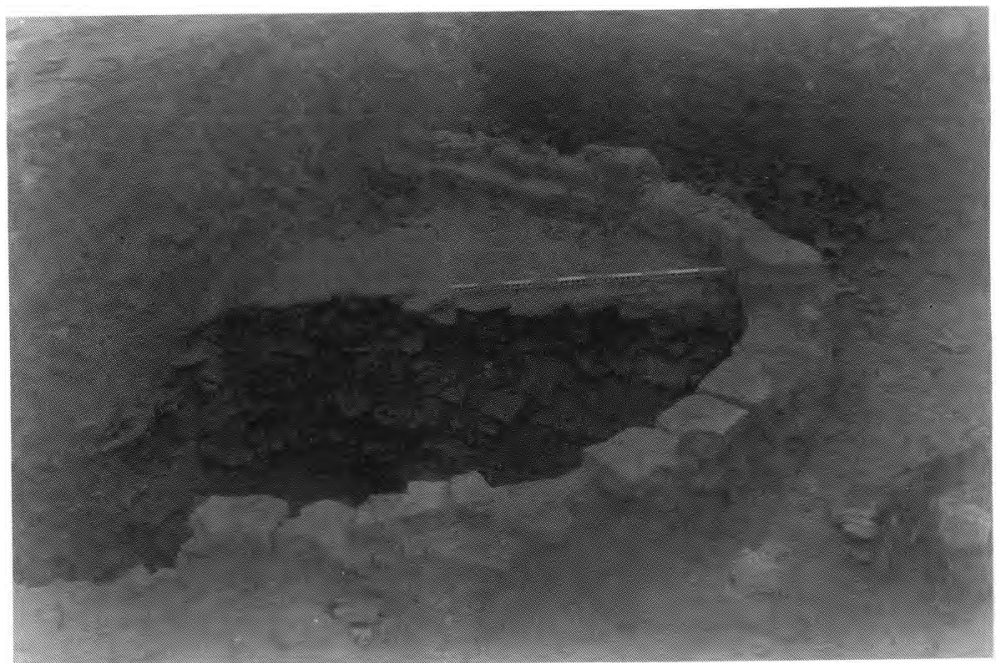

FIG. 4

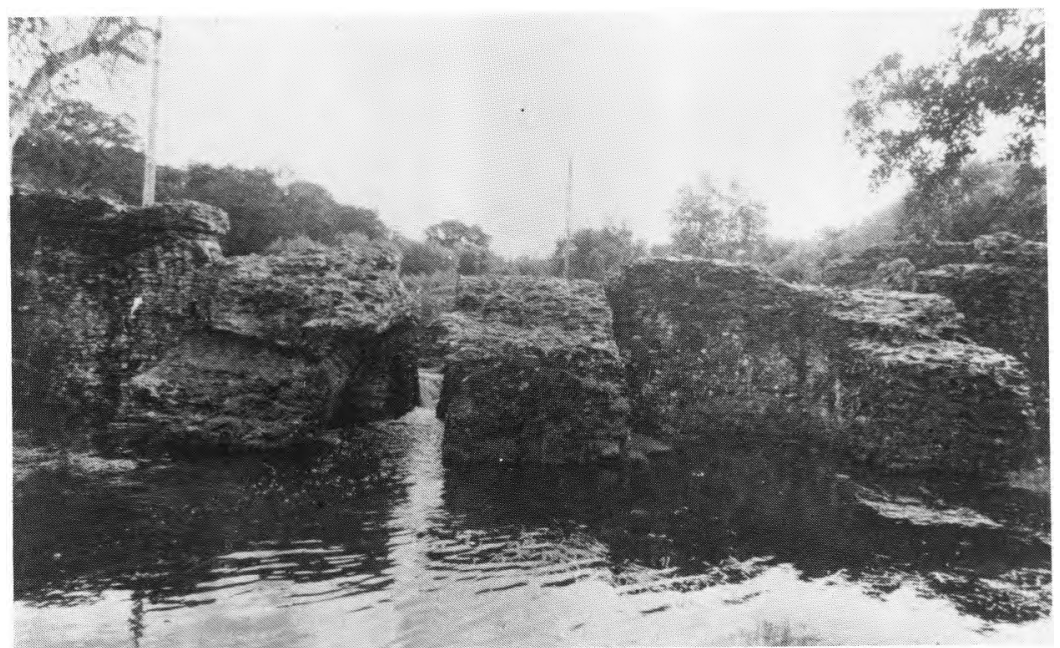

FIG. 5 


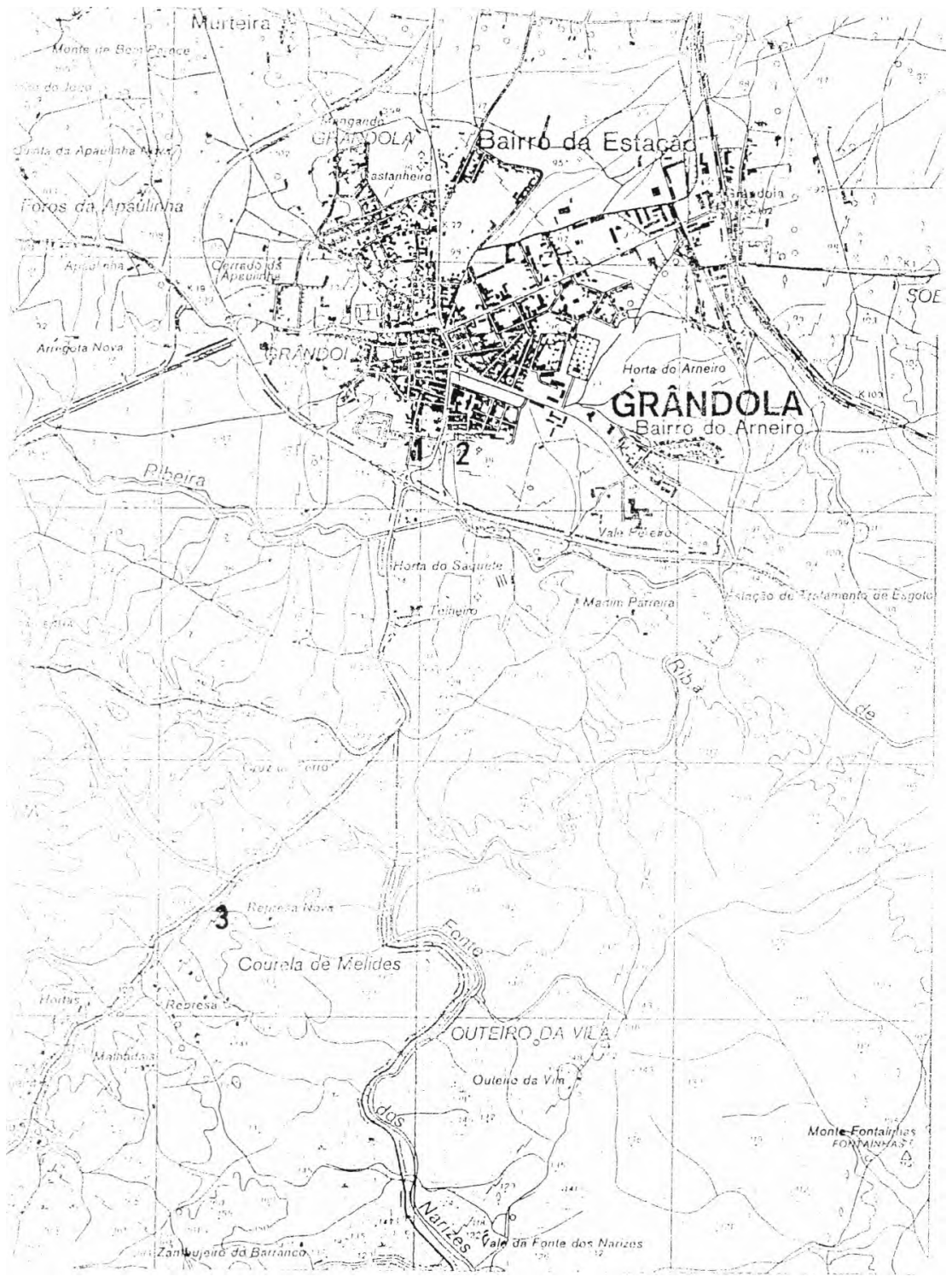

1- Estaçao Romana do Cerrado do Castelo

2- Necro'pole Romana do Cerrado do Arraial

3- 3arragem Romana do Pego da Moura (Represas ) FIG. 6 


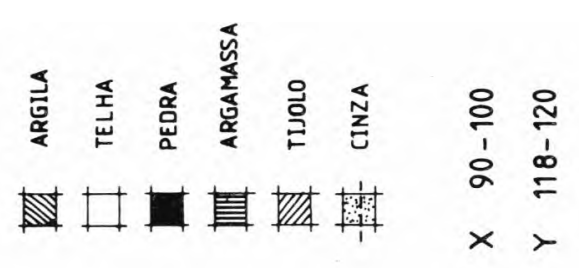
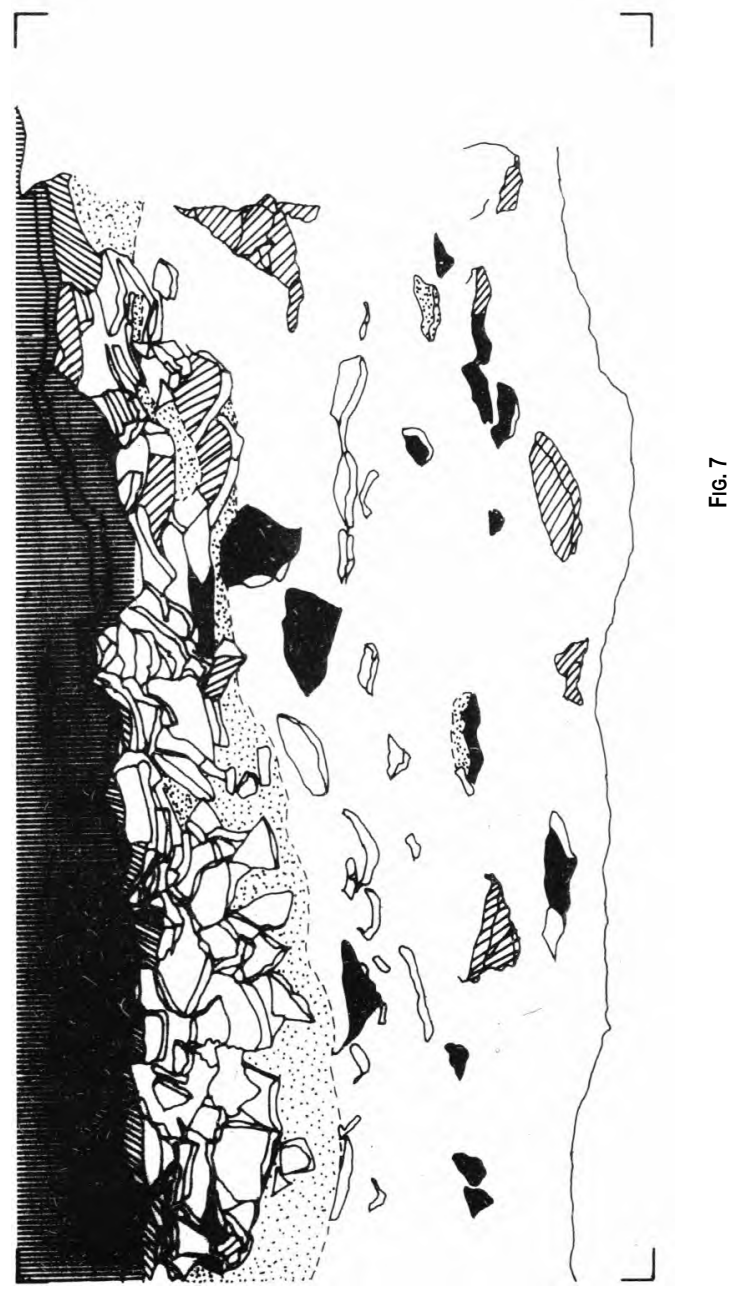

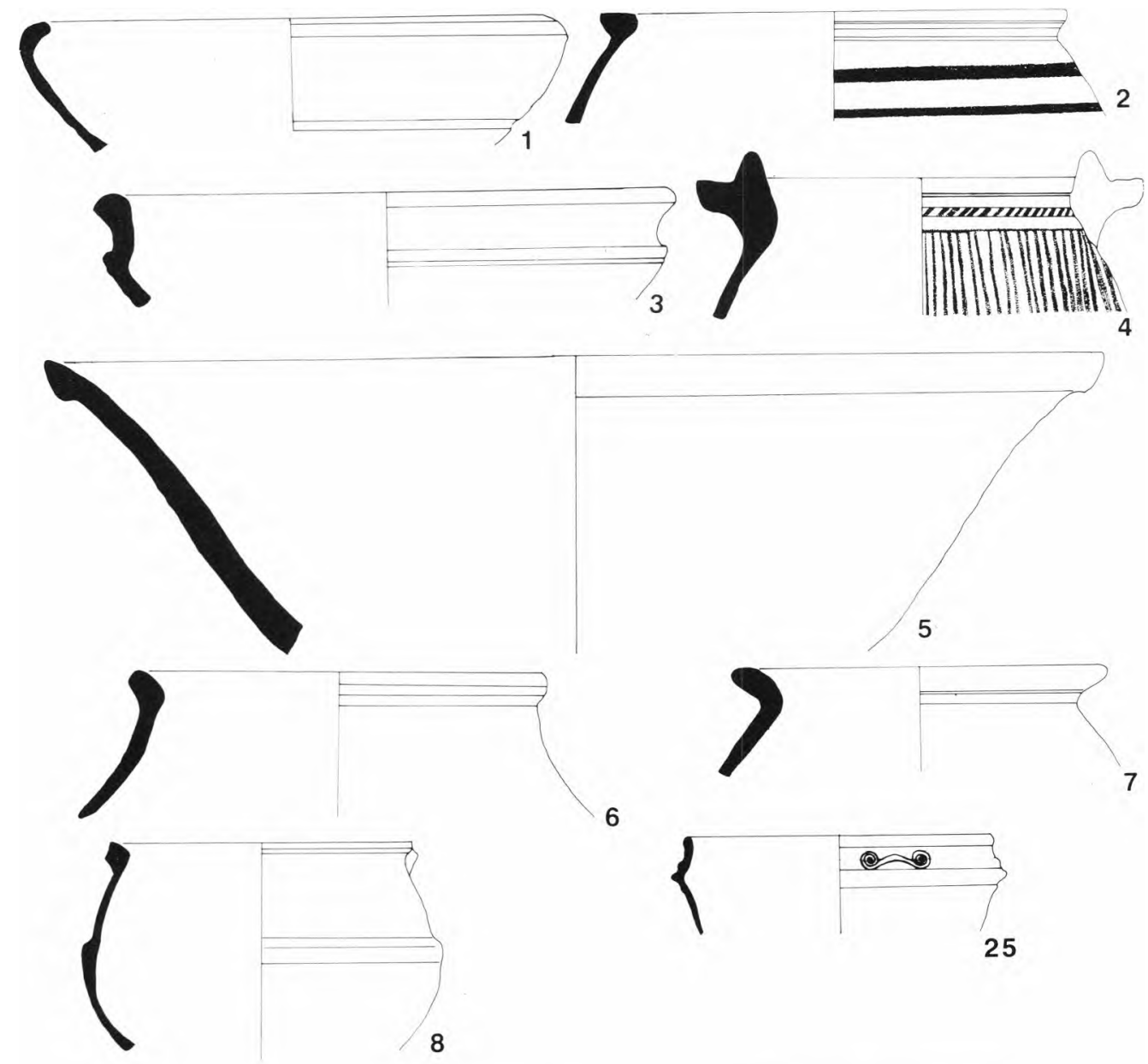

6
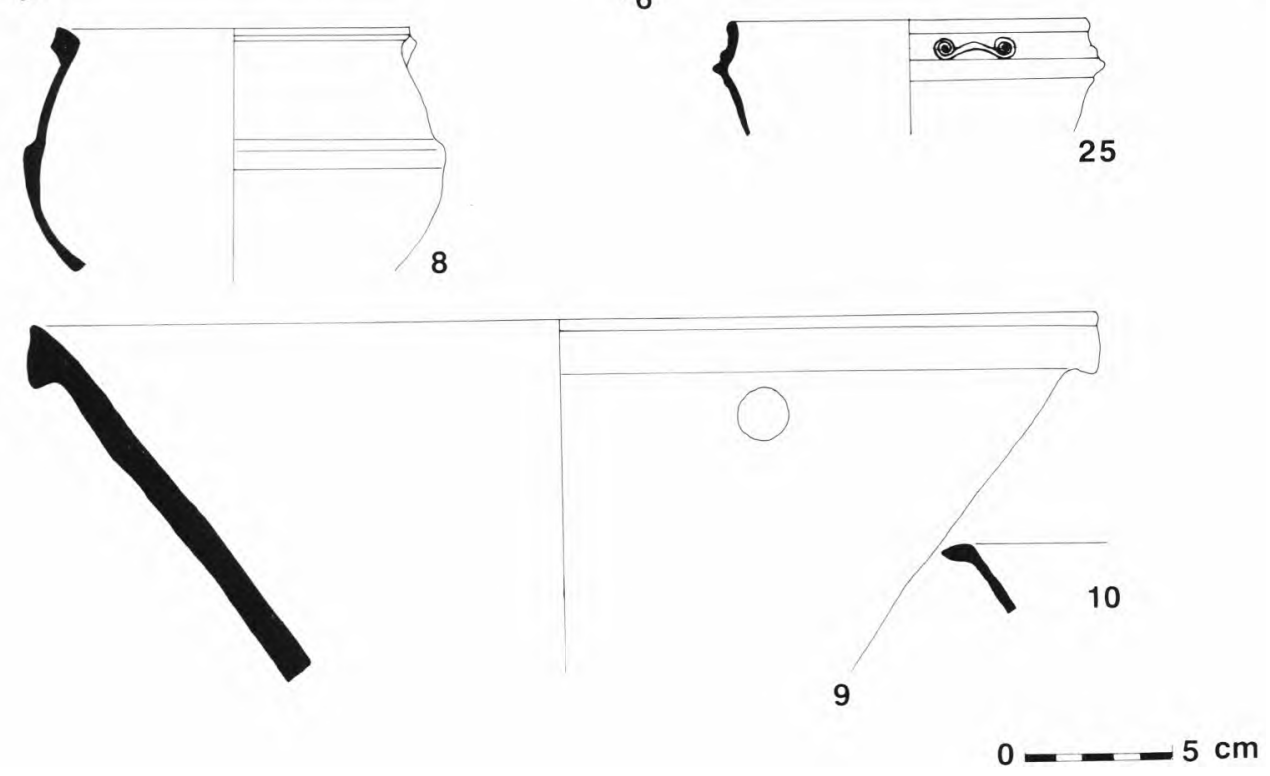

FIG. 8 

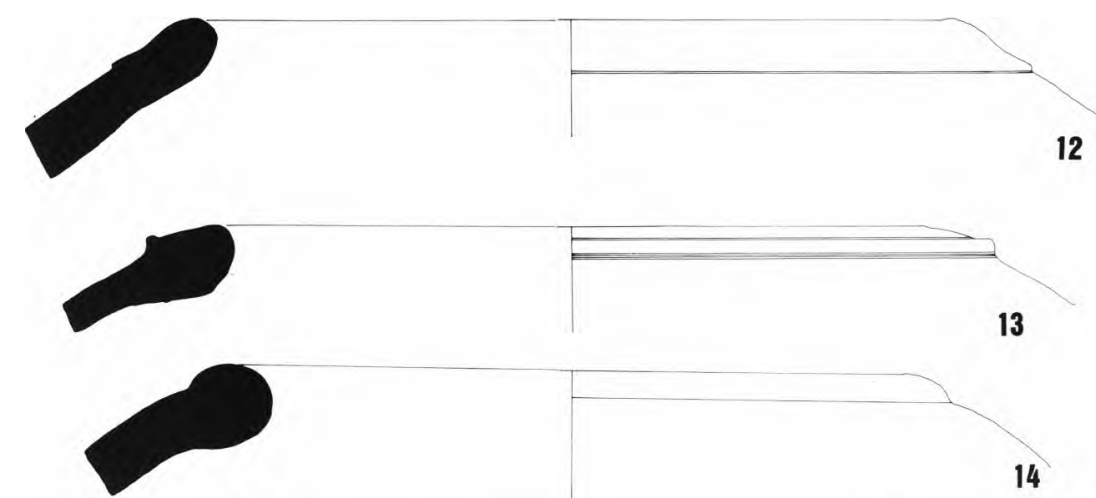

13

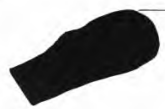

14

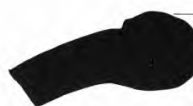

16

15

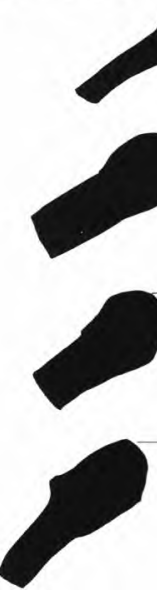

19

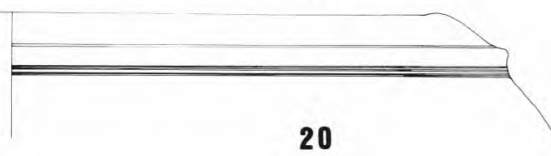

FIG. 9 


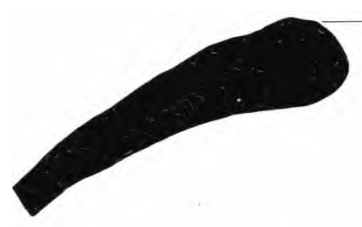

\section{1}

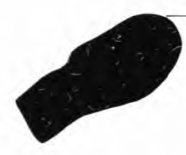

22

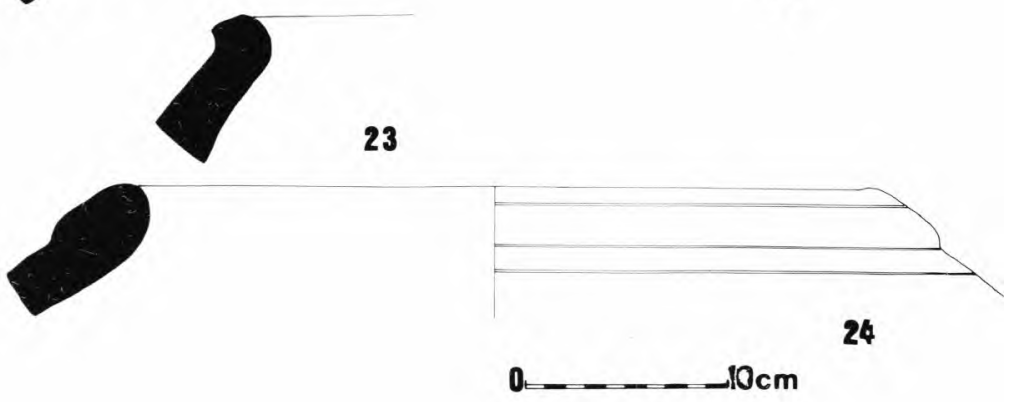

FIG. 10 


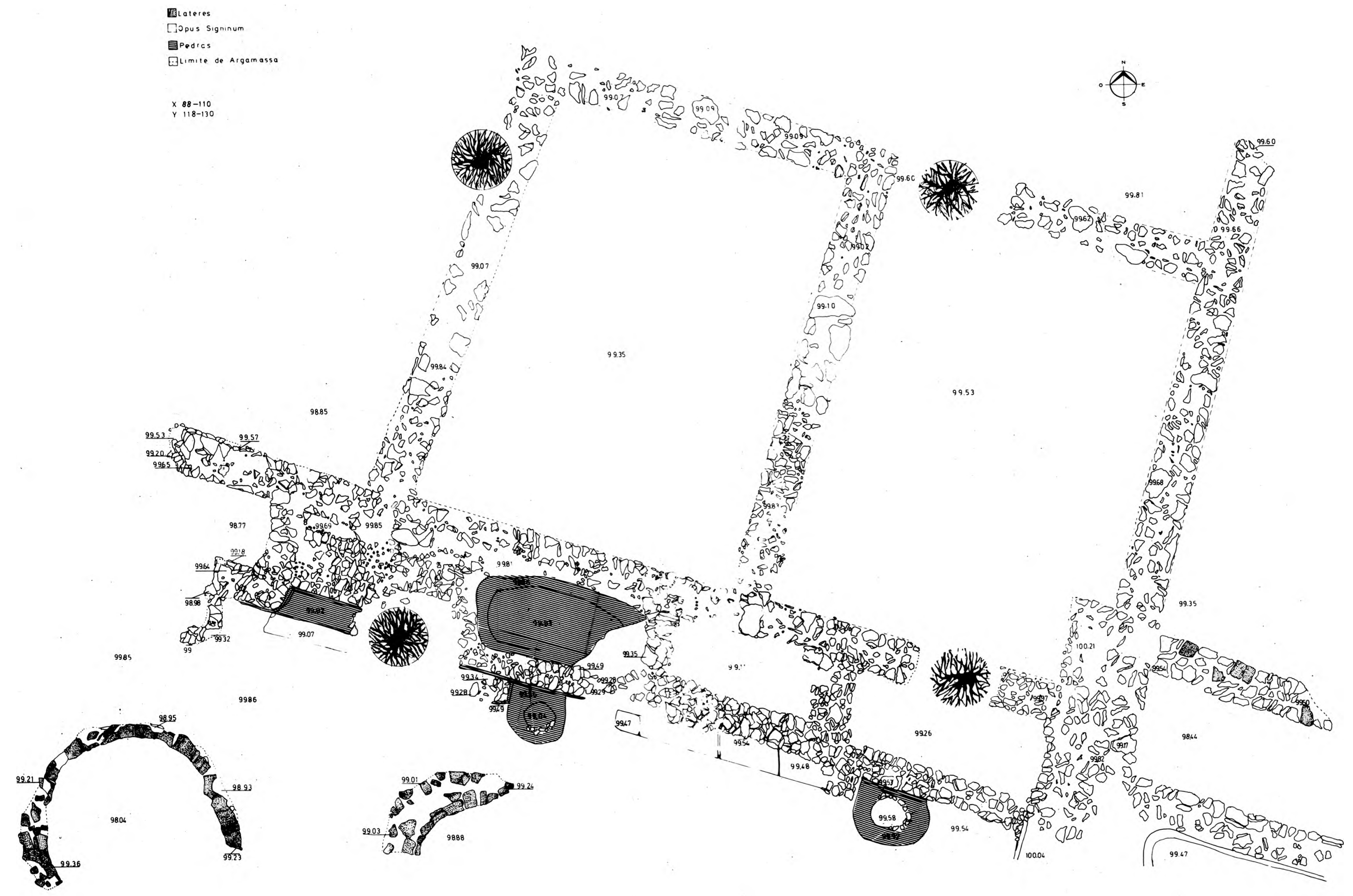

